\title{
Atendimento Psicológico às Mulheres em Situação de Violência nas Políticas Públicas
}

\author{
Atención Psicológica a las Mujeres en Situación de Violencia en las Politicas Públicas
} Psychological Assistance to Women in Situations of Violence in Public Policies

\author{
Madge Porto \\ Universidade Federal do Acre, Rio Branco, Acre, Brasil \\ madgeporto@gmail.com
}

\begin{abstract}
Resumo
O objetivo deste estudo é apresentar como um grupo de psicólogas avalia as orientações oficiais para o atendimento psicológico às mulheres em situação de violência no que se refere ao atendimento em psicologia na equipe multiprofissional. Para tal, foi realizada uma pesquisa de campo na qual foram entrevistadas 12 psicólogas. Utilizouse a Análise de Conteúdo definindo-se duas categorias de análise que apontam o que é omisso nas orientações para a intervenção em psicologia: 1) Promoção do empoderamento pessoal; e 2) Discriminação das atribuições profissionais da psicologia. Foi identificado que as orientações oferecidas para as ações em psicologia nas equipes multiprofissionais nos serviços especializados não são adequadas, e o papel da psicologia apresenta-se ambíguo e contraditório.
\end{abstract}

Palavras-chave: violência contra as mulheres; psicologia; abordagem de tratamento interdisciplinar.

\section{Resumen}

El objetivo de este estudio es presentar cómo un grupo de psicólogas evalúa las orientaciones oficiales para la atención psicológica a las mujeres en situación de violencia con relación a la asistencia psicológica en el equipo multiprofesional. Para ello, se realizó una investigación de campo en la que se entrevistó a 12 psicólogas. Se utilizó el Análisis de Contenido definiendo dos categorías de análisis que apuntan lo que es omiso en las orientaciones para la intervención en psicología: 1) Promoción del empoderamiento personal; y 2) Distinción de las atribuciones profesionales de la psicología. Se identificó que las orientaciones ofrecidas para las acciones en psicología en los equipos multiprofesionales en los servicios especializados no son adecuadas, y el rol de la psicología se presenta ambiguo y contradictorio.

Palabras clave: violencia contra las mujeres; psicología; enfoque de tratamiento interdisciplinario.

\section{Abstract}

The goal of this study is to present how a group of psychologists evaluates the official guidelines for psychological assistance to women in situations of violence regarding psychological care in the multiprofessional team. In order to do that, a field research was carried out in which 12 psychologists were interviewed. Content Analysis was used to define two categories of analysis that point out what is missing in the guidelines for intervention in psychology: 1) Promotion of personal empowerment; and 2) Discrimination of professional attributions of psychology. It was identified that the guidelines offered for psychological practice in multiprofessional teams in specialized services are not adequate, and the role of psychology is ambiguous and contradictory.

Keywords: violence against women; psychology; approach to interdisciplinary treatment. 
O serviço 180 da Secretaria de Políticas para as Mulheres (SPM) mostrou, em 2010, o atendimento de 108.546 casos de violência contra as mulheres no Brasil (Dieese, 2011). Na publicação mais recente da SPM (Brasil, 2015) sobre os dados do serviço, observa-se que $75,07 \%$ dos casos a violência ocorre com uma frequência de mais de uma vez por semana, o que segundo o documento é uma frequência muito alta; além disso, constata-se que, em $37,05 \%$ dos casos atendidos, as mulheres convivem há mais de 10 anos com o agressor.

Esses dados apontam algumas questões relevantes para o estudo ora apresentado: 1 ) a magnitude da violência, 2) o tempo que as mulheres levam para denunciar, e 3) a ocorrência sistemática das situações de violência ao longo de muitos anos.

Diante dessas constatações, apresenta-se relevante avaliar as políticas públicas para o enfrentamento deste tipo de violência. E, nesse contexto, pensar sobre atendimento psicológico como uma das intervenções para o enfrentamento à violência contra as mulheres, principalmente porque faz parte da política - como se pode perceber nos documentos publicados a partir de 2003 (Brasil, 2003, 2005a, 2005b, 2006a, $2006 \mathrm{~b}$ ) -, que o atendimento às mulheres em situação de violência nos serviços especializados (casas-abrigo e centros de referência) seja feito por uma equipe multiprofissional, composta por psicóloga/o, assistente social e advogada/o, e que algumas orientações sejam propostas para o desenvolvimento do trabalho especializado.

Porto e Bucher-Maluschke (2012), ao analisarem o discurso presente nesses documentos, destacam que as orientações propostas pela SPM a serem desenvolvidas pelas psicólogas apresentam-se contraditórias e confusas - como a indicação indiferenciada de teorias da Psicologia, inclusive as que partem de pressupostos e visão de mundo distintos em seus fundamentos -, apontando ser necessário definir qual o papel do atendimento psicológico nas políticas para mulheres em situação de violência. Com base nessa avaliação, a pergunta relevante é: como seria a avaliação das psicólogas que realizam atendimentos às mulheres vítimas de violência sob as orientações oferecidas pela SPM?

Para conseguir responder a essa questão, foi preciso ampliar o acesso a estudos que tomassem como foco a intervenção de psicólogas neste contexto específico (Machado, 2004; Oliveira e Souza, 2006; Hanada, D’Oliveira, e Schraiber, 2008, 2010; Diniz, 2011). Porém, observou-se que no Brasil existem poucos estudos que abordam o atendimento psicológico a mulheres vítimas de violência. Isso foi identificado após exaustiva busca realizada para fins de identificação do estado da arte para a pesquisa ora apresentada entre os anos 2010 e 2016. A busca foi realizada tanto em periódicos científicos, como Scientific Electronic Library Online (Scielo), Periódicos Eletrônicos de Psicologia (Pepsic) e Portal de Periódicos Capes, quanto em bancos públicos de dissertações e teses.

Foram feitas buscas utilizando os descritores/ palavras-chave 'atendimento psicológico' e 'violência contra as mulheres'. No banco de teses e dissertações foram encontrados 22 trabalhos; porém, destes apenas um explicita o tema objeto deste estudo - o atendimento psicológico para mulheres em situação de violência -, mas não se refere aos serviços especializados e faz foco nas questões do racismo.

Dentre os periódicos identificados como referindo de alguma forma o atendimento psicológico no contexto da violência contra as mulheres, há o trabalho de Oliveira e Souza (2006), que apresenta as concepções de gênero e violência conjugal entre psicólogos/as que atendem a mulheres e/ou homens em situação de violência conjugal em serviços especializados no Espírito Santo, concluindo que há “... indícios da utilização de uma perspectiva relacional na análise da violência entre cônjuges" (p. 44).

No entanto, este não é o único pressuposto, pois há também os estudos que defendem a inclusão da ótica de gênero nas intervenções em Psicologia, como o realizado por Diniz (2011), que tenta destacar a desigualdade de poder existente nas relações conjugais mediadas pela violência e a importância dessa perspectiva para se pensar o trabalho da Psicologia. Contudo, esta justificativa é entendida por Oliveira e Souza (2006) como 
uma argumentação dualista, quando paralelo a esse entendimento não se percebem as questões relacionais envolvidas nesse conflito.

Nesse contexto, percebe-se um conflito de perspectivas, uma relacional e outra sóciohistórica, a partir da leitura da realidade apoiada em diferentes referências teóricos, o que promove a necessidade de ter clareza sobre os pressupostos que fundamentam os resultados das pesquisas.

Pode-se considerar que o argumento "(...) homens e mulheres sofrem, praticam e sentem a violência em proporções variadas" (Oliveira \& Souza, 2006, p. 46) é importante para definir o tipo de trabalho que será desenvolvido pelas psicólogas ou psicólogos. Todavia, faz-se necessário considerar que as experiências de violência vivenciadas não se dão por influências essenciais no processo de subjetivação de mulheres e homens. Em outras palavras, a mesma desigualdade que coloca as mulheres em uma situação de vulnerabilidade diante da violência promoveu formas de estar e se relacionar com esse contexto em que elas também se expressam e significam o que vivenciam de várias formas, e por sua vez definem qual o papel dos homens nessa relação.

Hanada, D’Oliveira, e Schraiber (2008) apresentam, em um estudo realizado em São Paulo, as limitações dos serviços especializados oferecidos às mulheres em situação de violência, destacando que o resgate ou fortalecimento da autoestima no contexto da violência contra as mulheres deve ser o de empoderamento ou empowerment. As autoras definem empoderamento a partir da concepção feminista, como “(...) fortalecimento das mulheres no sentido da redistribuição de poder em favor delas, sendo necessárias mudanças na ideologia patriarcal, nas estruturas das instituições sociais (...) que reforçariam e perpetuariam a disseminação de gênero e iniquidades sociais". (p. 6).

Para Hanada et al. (2008), os/as psicólogos/ as dos serviços especializados não trabalham a partir desse entendimento de empoderamento. Estas autoras argumentam que as psicólogas que participaram do estudo trabalham a autoestima como algo do plano pessoal, individual, e concluem que, por isso, a intervenção é inadequada. Para elas, o papel do/as psicólogo/a seria o de trabalhar pelo que chamam empoderamento em termos políticos, e não pessoal ou subjetivo.

Nesse ponto, podem-se destacar duas questões para serem discutidas com base nos pressupostos destacados no texto dessas autoras: 1) a separação do que é político e do que é pessoal, e 2) a defesa de uma intervenção em Psicologia fundada apenas em uma referência feminista, sendo as referências da Psicologia desnecessárias ou mesmo inadequadas para a intervenção psicológica. Ou seja, como se fosse necessário ter uma posição feminista militante para se fazer o trabalho em Psicologia

Essas posições apresentam a Psicologia como uma ciência e uma profissão que, a priori, aliena e não promove emancipação social nem política das mulheres que sofrem violência, entendendo que a única solução de conflitos complexos seria a defesa política de direitos promovida por um movimento social.

Outra perspectiva trabalhada por Hanada et al. (2008) foi a apresentação da avaliação de algumas das normas propostas pela SPM para o atendimento nos serviços especializados, as quais serão analisadas mais adiante, pois são o ponto central do estudo que ora se apresenta.

Hanada, D'Oliveira, e Schraiber (2010) referem ainda que o/a psicólogo/a está presente e é solicitado a participar dos serviços especializados, e que poderiam ter como elemento específico de seu trabalho o compartilhamento dos saberes teórico e da prática da Psicologia com a equipe nas situações de supervisão. Nesse ponto, também é possível indagar por que o psicólogo compartilharia seus conhecimentos, já que esses são entendidos como não adequados ao trabalho a ser realizado?

As autoras dizem também que as psicólogas ou psicólogos consideram ações exclusivas da categoria as intervenções "essencialmente clínicas" (p. 54), e que, quando não desenvolviam essas atividades, suas intervenções não se diferenciavam da prática dos outros profissionais da equipe. Hanada et al. (2010) percebem ainda haver uma indefinição nas orientações apresentadas às psicólogas e psicólogos; porém, não deixam claro quanto a: 
qual seria a atribuição específica de psicólogas e psicólogos nessas políticas; e, como trabalhariam a partir do conceito de empoderamento de forma a produzir um resultado que a ação de outro profissional não tivesse condições de fazer e sem a necessidade de focar no sofrimento psíquico com base nas teorias cunhadas na Psicologia. Pois, se não há a exigência de uma intervenção com algum tipo de especificidade, não seria preciso demandar trabalho de profissionais da psicologia. Qualquer um poderia realizar.

Hanada et al. (2010) afirmam no texto que é preciso definir as atribuições de psicólogas e psicólogos nos serviços especializados e nos não especializados, mas não apresentam qual seria a atribuição para além do que entendem ser uma ação tradicional da Psicologia, qual seja a intervenção clínica; como seria o foco de trabalho no empoderamento se o objeto de intervenção fosse o sofrimento psíquico causado pela experiência da violência e que, por fim, o trabalho demandando pela política pública para mulheres em situação de violência fosse algo que exigisse, de fato, ter uma graduação em psicologia. E o argumento apresentado fica ainda mais frágil, principalmente porque destacam que, quando estes/as profissionais não fazem o que é tradicional da Psicologia, passam a realizar as mesmas tarefas dos outros membros da equipe. E aqui cabe a pergunta: por que é preciso ter psicólogos/as nesses serviços? Para fazer o quê?

Por fim, o texto de Hanada et al.(2010) parece defender, de forma implícita, que há um lugar para os/as psicólogos/as nessas políticas; eles são chamados para atuar, mas não sabem o que fazer, já que não devem atuar de forma clínica. Todavia, o que poderiam fazê-lo não ficou explicitado, e os que trabalharam com base em referências que não contemplaram as teorias da Psicologia atuaram de forma indiferenciada de outros profissionais, fazendo o que estes também poderiam fazer. A intervenção clínica, assim, é entendida por essas autoras como não sendo adequada ao trabalho específico por definição, e não por conta de uma avaliação com resultados exitosos de experiências realizadas a partir de uma intervenção em que o empoderamento fosse trabalhado nos termos definidos por elas, como a redistribuição de poder em favor das mulheres e de mudanças na ideologia patriarcal apenas.

Por fim, Machado (2004), em um estudo que se refere à experiência de Portugal, coloca o foco de sua análise nas consequências do trabalho, nesse contexto de violência contra as mulheres, para as psicólogas. A autora entende que o atendimento psicológico às mulheres vítimas de violência promove na psicoterapeuta/psicóloga dilemas teóricos, técnicos e emocionais. Dentre os dilemas vividos pelas psicólogas, pode-se destacar o que se apresenta no conflito entre a formação em Psicologia e as orientações dos serviços especializados para mulheres em situação de violência, que fica implícito nos estudos já citados sobre o assunto (Hanada et al., 2008, 2010; Machado, 2004), ou seja, uma formação com base em teorias psicológicas para trabalhar o sofrimento psíquico e uma orientação que nega essa referência e tem como princípio teorias da Sociologia e/ou da História.

Dessa forma, o objetivo deste artigo é apresentar como psicólogas que atendem a mulheres em situação de violência avaliam os papéis atribuídos à equipe multiprofissional nos documentos de orientação específicos da SPM.

\section{Método}

A partir do objetivo definido, a proposta metodológica estabelecida foi de um estudo qualitativo, descritivo-analítico, dada a escassez de referências bibliográficas que tratam especificamente do atendimento psicológico às mulheres em situação de violência, como já foi referido anteriormente. Assim, como técnica para a investigação, foi realizada uma entrevista semiestruturada presencial. Investigaram-se temas como a forma de identificação do caso 
de violência, a intervenção realizada, o que se conhece dos documentos da SPM; e, em seguida, foram apresentadas as orientações encontradas em manuais, portarias e normas técnicas, que indicavam como a intervenção em Psicologia deveria ser desenvolvida no trabalho com as mulheres que sofrem violência. Vale destacar que o projeto de pesquisa foi aprovado pelo Comitê de Ética em Pesquisa com Seres Humanos da Universidade Federal do Acre em 13.10.2010 ( ${ }^{\circ}$ do protocolo 23107.014891/2010-79).

\section{Participantes}

Todas as psicólogas inscritas no Conselho Regional de Psicologia 20a Região - CRP 20 seção Acre que ofereceram à instituição um endereço eletrônico para comunicação foram convidadas a participar da entrevista por meio de uma mensagem eletrônica (e-mail).

Após as 18 respostas à mensagem eletrônica, foram realizadas as tentativas para marcar as entrevistas pessoais no período de fevereiro a março de 2012. Neste tempo, foi possível realizar 12 entrevistas com as psicólogas que se disponibilizaram para tal. Convém destacar que todas as entrevistas foram realizadas pela pesquisadora nos locais indicados pelas entrevistadas, e foram gravadas em áudio. Destas 12 psicólogas entrevistadas, seis foram psicólogas que tinham experiência em serviços da rede de enfrentamento à violência contra as mulheres, em especial o centro de referência e a casa-abrigo, e seis psicólogas nunca haviam prestado assistência em serviço especializado de atendimento a mulheres, mas já tinham atendido ou atendem a mulheres em situação de violência em sua prática clínica.

\section{Procedimento de análise}

As entrevistas foram transcritas e analisadas com base no método de Análise de Conteúdo (Bardin, 1977/2011). A unidade de análise ou unidade de significado trabalhadas foram os temas atendimento, trabalho em equipe, atendimento psicológico e equipe multiprofissional. Após separar as partes do texto que se referiam a esses temas, foi organizada uma tabela com colunas indicando a entrevistada, sua fala, e o que era destacado sobre a atuação da equipe no serviço para identificar a mensagem produzida em seu texto. Posteriormente, as unidades de análise de conteúdo foram submetidas à classificação que produziu duas categorias temáticas, que serão descritas na sequência. Observou-se que as falas das entrevistadas destacavam duas questões centrais: o que exatamente cada profissional da equipe deveria fazer e o incômodo por existir uma sobreposição de atribuições, que dificultava o trabalho. Para ilustrar as categorias de análise observadas, foram escolhidas as falas que representavam o conteúdo que deu origem à nomeação da categoria de análise de forma mais explícita.

\section{Resultados e Discussão}

As psicólogas entrevistadas fizeram uma avaliação crítica do trabalho em rede e em equipe multiprofissional destacando conflitos e pontos a serem esclarecidos nas atribuições inferidas e explicitadas nos documentos da SPM. A análise de conteúdo das entrevistas evidenciou, a partir da convergência da fala de pelo menos três quartos das entrevistadas, com relação ao papel da Psicologia na equipe multiprofissional da política de enfrentamento à violência contra as mulheres duas categorias: 1) promoção do empoderamento pessoal, e 2) discriminação das atribuições profissionais da Psicologia.

\section{Categoria 1 - Promoção do empoderamento pessoal}

Para as informantes, se faz necessário a incorporação de um processo de empoderamento pessoal que não se constitui apenas por acesso a informações sobre direitos e políticas públicas. 
(...) pra mima a Psicologia ela pode tá trabalhando no fortalecimento, no empoderamento dessa mulher vítima, mas nunca é distanciada das outras áreas. (...) Porque trabalhar as nuances, trabalhar o mundo interno (...)." (Malena ${ }^{1}$ - psicóloga de serviço não especializado).

Psicólogas teriam como foco a atenção ao sofrimento psíquico, às dores emocionais, aos desejos contraditórios que perpassam a relação vivida.

Malva fala que há um trabalho feito em equipe, as ações educativas, que classifica como ações preventivas:

(...) era feito com outros profissionais as palestras de prevenção nas escolas, nos cursos mesmo, na abertura dos cursos. Então era feito com advogada, com assistente social as palestras de prevenção e informação falando da violência, do ciclo violência, falando da Lei Maria da Penha, do próprio, dos próprios, da própria relação de gênero, da desigualdade de gênero." (Malva - psicóloga de serviço especializado).

Para a maioria das psicólogas entrevistadas, as ações educativas e preventivas poderiam ser desempenhadas por qualquer profissional, desde que treinados/as. A ação de conscientização da opressão de gênero pode ser considerada uma delas, conforme consta nos documentos de orientação da SPM (Brasil, 2003, 2005a, 2005b, 2006a, 2006b), e é afirmada por Hanada et al. $(2008,2010)$ como promotora de empoderamento. Contudo, ao mesmo tempo que, a promoção da conscientização da opressão de gênero é uma ação que pode integrar psicólogas ampliando as possibilidades de intervenção em Psicologia, pode, paradoxalmente, dificultar as intervenções não só em Psicologia, mas da própria política pública. Isso porque poderemos perguntar: quem logrará se dispor a escutar o sofrimento proveniente do conflito entre não querer ou não conseguir encaminhar o que o serviço de apoio propõe e orienta como necessário, ou seja, o que as mulheres têm como direito e que precisariam fazer para demonstrar seu empoderamento? Essa pergunta se faz necessária diante os estudos de Brandão (1998) e Machado (2004), que apresentam as contradições dos desejos e das escolhas de mulheres que sofrem violência. A experiência clínica também demonstra isso, além dos dados alarmantes de desistência dos processos. Recepcionar bem as mulheres nos serviços, informar e oferecer-lhes oportunidades de aprendizagem são ações fundamentais no processo promoção de mudança; porém, diante dos resultados de retorno aos serviços (Garcia, Ribeiro, Jorge, Pereira, \& Resende, 2008) e da magnitude das desistências dos processos, há de se ter um espaço para acolher um fenômeno recorrente nas situações de violência contra as mulheres: os recuos nos processos de enquadramento do agressor, ou seja, quando as mulheres vão às delegacias e promotorias para desistir do processo criminal, como já apontava o estudo de Brandão (1998).

Há o entendimento de um trabalho que se complemente, pois o que importa é o que se pode contribuir de diferentes formas, como destaca Açucena (psicóloga de serviço especializado): "Precisa de ter uma equipe multiprofissional. É que os olhares são diferentes.".

Acolher o desespero, trabalhar a frustração, a realidade, o limite e a incompletude (Menezes, 2012) poderia ser o foco do trabalho de psicólogas nesse contexto. Assim, uma questão se destaca: o trabalho a ser realizado diante dessa frustração se refere ao que a mulher deseja, a que o marido mude, por exemplo, como observou Brandão (1998)? E, se a mudança esperada não se efetivar, fazendo com que a mulher se depare com uma desilusão - de que não consegue realizar esse desejo -, e ela se nega a enfrentar esse limite? Talvez, as duas questões precisem ser trabalhadas. Para essas mulheres, pode-se ariscar, há demanda por um trabalho em Psicologia Clínica. Este

1 Os nomes apresentados são fictícios. 
parece se fazer necessário, juntamente com as outras atividades propostas, como conhecer seus direitos e reconhecer a violência vivenciada, que nem sempre é identificada, por exemplo. Também teria o papel de trabalhar para o empoderamento destas, como refere Malena (psicóloga de serviço não especializado): "Eu acredito que o papel da Psicologia é do empoderamento da mulher. O que que é esse empoderamento? É trabalhar o processo de conscientização do lugar que ela ocupa hoje (...)"., e reforça Nora:

Eu acho que, que o suporte de empoderar essa mulher, entendeu? No sentido de fazer ela se ver, se gostar, sabe? Eu acho que é muito importante ela perceber qual que é o papel dela, o contexto dela dentro desse grupo. (...) O que que ela é nesse momento, (...) Você precisa se olhar; você precisa se perceber; você precisa ter felicidade pra você continuar vivendo. Ninguém vive se anulando a vida inteira, ninguém vive a vida do outro, entendeu? E o outro não vai te suprir. Você é um ser humano único. Então são coisas assim que é muito importante você tá ciente disso. Eu acho que nesse momento o psicólogo entra assim essencialmente em grande... Com grande força na vida dessa pessoa, por quando eles vêm, elas vêm nos procurar elas tão assim num momento de muita fragilidade (...) (Nora - psicóloga de serviço não especializado).

Para as entrevistadas, o empoderamento da mulher passa também pelas questões da subjetividade, ao contrário do que defendem as orientações da SPM e Hanada et al. (2008, 2010) como, unicamente, resultado de uma conscientização política. É importante destacar que a conscientização política da opressão de gênero poderia ser pensada como um trabalho que qualquer um dos componentes da equipe poderia realizar, desde que devidamente preparado, e não como atribuição que as psicólogas teriam de assumir. Dessa forma, o trabalho de promoção do debate do empoderamento poderia ser assumido por outra profissional da equipe que trabalharia esse empoderamento do ponto de vista da compreensão das origens das inequidades de gênero e as ações do protocolo de proteção, e a psicóloga do ponto de vista da subjetividade trabalharia como os dispositivos amoroso e materno e as tecnologias de gênero (De Lauretis, 1987; Swan, 2006; Zanello, 2016), que constituem desejos e modelos que impõem sofrimento, devendo também ser compreendidos e superados.

O trabalho de psicólogas poderia, dessa forma, contribuir com um processo de intervenção multifacetado por intervenções de outras categorias profissionais, fazendo foco no sofrimento psíquico.

\section{Categoria 2 - Discriminação das atribuições profissionais da Psicologia}

As psicólogas voluntárias de pesquisa destacam que é preciso definir o papel da Psicologia tanto no que se refere aos locais onde as psicólogas desenvolvem seus atendimentos na rede, quanto às outras profissionais da equipe:

(...) Então, são serviços diferentes que precisariam ter formas de atendimentos diferentes e ter uma proposta mais clara. (...) Então, ela vai chegar lá na Delegacia da Mulher, então essa psicóloga ela vai fazer o quê? Ela vai fazer uma acolhida? (...) Mas definir, a partir do fluxo, o que é papel de cada profissional. (...) Qual é o papel nesses serviços, eu tenho questionado muito isso, porque se a mulher sai (...) ali ela decidiu, ela passou uma situação de violência, vai lá pra Delegacia da Mulher, aí ela chega lá, vai fazer o BO, ela vai passar por uma psicóloga, é pra quê? Aí ela sai, o processo vai pra Vara. Chega lá na Vara ela vai falar tudo aquilo de novo. Vai repetir mais uma vez. Aí ela vai pra uma outra psicóloga. Aí essa psicóloga vai lá, escuta, bá-bá-bá. É pra quê? (...) Então, às vezes, assim, não aconteceu de passar por quatro, mas acontece de passar por três psicólogas. Nem essa mulher sabe pra que que é, entendeu? Acho que nem o profissional sabe, de fato, praquê. Porque eu entendo que é... Deva 
ter alguma atribuição pra essas profissionais nesses serviços. Mas é pra cumprir o quê? É pra cumprir uma determinação da justiça? É pra elaborar um parecer? Um laudo? O que é que a juíza tá pedindo, o que é que a delegada tá precisando? Entende? Então, assim, isso tá muito confuso (...).eu tava falando a questão dos mitos e preconceitos que o psicólogo vai só é... conversar, vai só ouvir. Essa, essa coisa banal. E aí todo mundo pode fazer. Poderia entre aspas. Quando a Psicologia é vista dessa forma. (...) Por outro lado, um relato da colega falando, que produz um relatório psicossocial na Vara. Aí esse relatório ele é generalista, ele não coloca nada específico da Psicologia. Aí isso acaba dando brechas, entendeu? Se o que tá escrito aqui não tem nada que seja específico e relacionado à Psicologia, então qualquer um pode fazer. (...) E por que quê é psicossocial? $E$ aí, assim, dá margem, entendeu? Reforça porque eu acho que a gente já tem um desafio muito grande, que é romper com essa visão da Psicologia. (Macela - psicóloga de serviço especializado).

A entrevistada percebe uma sobreposição de papéis e de ações, das próprias psicólogas distribuídas na rede de enfrentamento à violência contra as mulheres, o que em última instância promove a revitimização pela falta de definição do que cabe a cada ponto da rede de atendimento, a cada psicóloga de cada serviço e de qual trabalho a ser desenvolvido, fazendo com que a mulher continue repetindo sua história de dor e sofrimento sem um objetivo definido.

A sobreposição de papéis também se observa quando se pensa sobre a pergunta de Macela: $E$ por que quê é psicossocial?

Mesmo existindo muitas indicações sobre a necessidade de se realizarem "atendimentos psicossociais" nesse tipo de serviço (Brasil, 2006a, 2006b), esses não são definidos na mesma proporção em que são demandados.

O Conselho Federal de Psicologia - CFP (2012) apresenta 'atendimento psicossocial' como “... a principal alternativa (...). Entretanto, é muito comum que se confunda a abordagem psicossocial com a psicoterapia. Nesse sentido, a psicoterapia como prática da(o) psicóloga(o) sistematizada e controlada por métodos e técnicas psicológicas reconhecidos pela ciência, pela prática e pela ética profissional. (...) O que distingue uma da outra são basicamente as formas de intervenção e os objetivos. Na abordagem psicossocial, estruturamse ações de atendimento e de proteção que propiciem condições para a superação da situação de violação de direitos. A(o) psicóloga(o) responsável pelo atendimento deve avaliar as peculiaridades de cada caso para decidir se o encaminhamento é para atendimento de serviço de saúde mental, ou se propõe um conjunto de atendimentos psicossociais no seu plano terapêutico. A abordagem psicossocial pode potencializar a atuação profissional, uma vez que essa ferramenta incorpora a dinâmica social na qual o indivíduo está inserido." (CFP, 2012, pp. 91-92).

A definição do CFP diferencia atendimento psicossocial da psicoterapia, considerando esta como intervenção embasada teórica e tecnicamente pelas teorias psicológicas. Todavia, o atendimento psicossocial é apresentado como se não fosse intervenção da Psicologia, sendo dessa forma uma intervenção que poderá ser realizada por outro profissional. A condição do conhecimento em Psicologia estaria para a identificação da necessidade de um encaminhamento para os serviços de saúde mental, diferente do que orienta SPM (Brasil, 2006b). Nas orientações para a intervenção nos serviços especializados, esta intervenção ficaria com as assistentes sociais. Contudo, o que faria uma psicóloga para estruturar “... ações de atendimento e de proteção que propiciem condições para a superação da situação de violação de direitos" que outro profissional não poderia fazer? Ou ainda: O que seria "um conjunto de atendimentos psicossociais no seu plano terapêutico"? Qual o plano terapêutico de uma psicóloga que não seja a psico... terapia? E mesmo que seja um plano terapêutico que tenha como objetivo de intervenção a superação da violação de direitos, seria melhor uma psicóloga desenvolvendo essa atividade? Por quê? Para fazer o quê? 
A publicação citada expressa que esse tipo de intervenção pode potencializar a atuação do profissional, justificando que assim haverá a incorporação da dinâmica social para o enfrentamento do problema. Aqui, há uma convergência com a análise de Hanada et al. (2008), ou seja, psicólogas não consideram os aspectos da vida como experiência social, ficando restritas aos elementos da subjetividade. A psicoterapia como prática da Psicologia legitimada pela teoria, pela ética e pela prática, não tem lugar nesse contexto, ficando as psicólogas para realizar algo que ainda não fica claro. Pode-se pensar que, se é para não fazer algo que tenha base em teorias psicológicas, não precisaria haver psicólogas nessa equipe.

Por fim, pode-se ainda questionar o que seria o "psi" do atendimento psicossocial, já que toda definição é para destacar a necessidade de uma intervenção referente às questões de ordem social presentes nas situações de violência contra as mulheres. Contudo, a afirmação de que "essa ferramenta (a abordagem psicossocial) incorpora a dinâmica social na qual o indivíduo está inserido" (CFP, 2012, p. 92), como se teorias psicológicas não considerassem a dinâmica social, pode ser questionada. Essa éumageneralização problemática, pois desconsidera algumas abordagens teóricas da Psicologia que faz exatamente o que está sendo demandado, ou seja, que "incorpora a dinâmica social na qual o indivíduo está inserido" - a Psicanálise é uma delas ${ }^{2}$.

Diante da definição de atendimento psicossocial do CFP, pode-se dizer que se trata de uma intervenção mais generalista, que de fato pode ser realizada por qualquer profissional, para o encaminhamento quanto à proteção da vida, da integridade física, sexual, mental e patrimonial, acesso a recursos materiais e à justiça. Uma atuação nos moldes das agências governamentais internacionais (Machado, 2004), e que pode ser o que promove essa sobreposição de papéis dos profissionais da equipe multiprofissional, que foi percebida pelas entrevistadas.

Por fim, há a sobreposição que é justificada pela necessidade dos trabalhos em grupo. Para as psicólogas, a intervenção em grupo se faz importante e não destitui a atuação clínica de psicólogas, necessariamente:

(...) grupos de atendimento onde outras mulheres falam sobre as suas experiências, onde outras mulheres falam das suas conquistas. Daquilo que mudou, daquilo que foi difícil, porque parece assim que, às vezes, no consultório quando a gente faz uma devolutiva, a sensação que dá é que, assim, é fácil você falar. Mas na hora de fazer é difícil. Então dessas mulheres também poderem ter acesso a outras mulheres que passaram pela mesma coisa, que passaram por muitas dificuldades, mas que pra elas foi possivel essa... Vencer algumas questões. Não todas, porque às vezes parece que a pessoa vai resolver, vai ficar um mar de rosas, vai ser uma vida cor de rosa. E a vida vai continuar sendo colorida de tudo que é jeito. Então eu acho que é muito... É fundamental o trabalho clínico, porque outras questões estão envolvidas aí. (...)" (Serena - psicóloga de serviço não especializado).

Mesmo nos trabalhos em grupo, que qualquer profissional poderá realizar, cada um poderá fazê-lo a partir de seu conhecimento. Psicólogas certamente poderão trabalhar além das intervenções educativas e grupos de apoio com grupos de psicoterapia. Vale destacar que, nesta última modalidade de trabalho em grupo, as assistentes sociais e/ou advogadas não terão como desenvolver, pois não terão instrumental teórico nem técnico para esse tipo de abordagem em grupo.

As atividades em grupo são ricas e, como disse Serena, promovem uma experiência que a intervenção individual não oferece. Contudo,

2 Como nos aponta texto como este: Broide, Jorge. (1992). A Psicoterapia Psicanalítica na rua realizada através de grupo operativo: a rua enquanto instituição das populações marginalizadas. Psicologia: Ciência e Profissão, 12(2), 24-33; Costa, J. F. (1984). Violência e Psicanálise. Rio de Janeiro: Graal. 
é importante destacar que trabalhos em grupo nos quais as participantes choram, desabafam, não necessariamente promovem a elaboração do sofrimento psíquico de forma a promover mudanças efetivas na vida da pessoa, pois esses grupos funcionam como possibilidade de catarse, que tem potencial terapêutico, mas não promovem a elaboração de um sofrimento como propõe uma psicoterapia, seja individual ou grupal, com seus objetivos e processos, em especial, com aquelas mulheres que continuam em situação de violência (Brandão, 1998, Garcia et al., 2008, Porto \& Bucher-Maluschke, 2014) mesmo após passarem pelos serviços da rede de enfrentamento à violência contra as mulheres.

Os diversos trabalhos em grupo, que podem ser realizados por outros profissionais da equipe multiprofissional, são capazes de favorecer momentos significativos e serem inclusive terapêuticos; contudo, esses profissionais não terão como planejar e manejar intervenções com objetivos de trabalhar questões da subjetividade como uma psicóloga ou psicólogo está preparado para fazer. É preciso entender, conhecer os processos psíquicos, como eles se desenvolvem e quais as técnicas para uma intervenção adequada em cada caso. Claro que há casos em que psicólogas ou psicólogos atuam de forma inadequada, o que pode ser fruto de má formação profissional (Bastos \& Gondim, 2010) e/ou má conduta ética; no entanto, isso não justifica que a existência de intervenções inadequadas sejam resolvidas limitando ou excluindo a possibilidade de atuação em psicoterapia, e estabelecendo que caberá à psicóloga ou psicólogo uma intervenção que qualquer profissional poderia realizar, como forma de resolver os problemas da formação.

Diante dessas observações, este artigo pretende destacar que os pressupostos da militância política feminista, que possibilitaram o desenvolvimento de teorias complexas sobre gênero (Arán, 2009; Bourdieu, 1998, 2005; Butler 1990, 1992; Rubin, 1993, Swain, 2006; Zanello, 2016) e que podem ser utilizadas para discutir os fenômenos da violência e as subjetivações articulando diversos fatores. Um desses fatores de articulação seria com as referências teóricas da Psicologia, de forma a construir possibilidades de respostas mais eficientes que as polarizações, a favor ou contra as psicoterapias no contexto das políticas públicas. Respostas simplistas para a resolução de problemáticas extremamente complexas parece não nos apresentar os melhores resultados.

\section{Considerações Finais}

O papel da Psicologia na equipe multiprofissional da política de enfrentamento à violência contra as mulheres é percebido como impreciso, ambíguo e em alguns momentos contraditório, quando se analisam as duas categorias estruturadas a partir das falas das entrevistadas.

O que se observou quanto ao que entendem as psicólogas sobre as atribuições profissionais nas intervenções junto às mulheres em situação de violência é que o trabalho precisa dar atenção ao sofrimento psíquico vivido pelas mulheres de forma a não se sobrepor às atribuições das outras profissionais, e de modo a não ter seu trabalho, no que é específico, confundido com outras intervenções necessárias. Vislumbra-se a necessidade de uma intervenção integral, que abranja vários aspectos necessários à resolução do problema, das questões de ordem social e jurídica às emocionais.

Assim, pode-se concluir que para essas profissionais o trabalho em equipe multiprofissional precisa se colocar de forma a ser complementar, pensando-se de forma coletiva as intervenções mais adequadas para o caso ou o momento, e não ter uma única forma de realizar a intervenção junto às mulheres.

A proposta de atendimento psicossocial parece que precisa de atenção. Além de desejarem mais clareza na sua definição, para que não se fique com uma orientação tão generalista, que mais 
confunde que orienta. Os resultados apontam que não será levando as psicólogas a atuarem de forma distante de sua formação, ou seja, em equipes multiprofissionais em que todos realizam as mesmas atividades, ou a atuarem em tarefas em que não se precisa de formação especializada em Psicologia, fazendo uma intervenção psicossocial. Quando psicólogas são chamadas a intervir no sofrimento psíquico de um grupo ou de uma pessoa, espera-se que a profissional possa trabalhar os processos intrapsíquicos nas suas relações com os contextos sociais, históricos e culturais, para dessa forma atuar de forma multi, inter, pluri ou transdisciplinar.

Talvez seja esse tipo de disposição para a definição de como se deve desenvolver determinado trabalho que traga dificuldades. Isso porque se apresenta que há apenas uma forma boa, ideal, correta e eficaz para realizar um trabalho, a intervenção psicossocial. Esta é colocada como intervenção a priori; entretanto, ao mesmo tempo defende-se a participação do profissional, sua autonomia e a necessidade da intervenção em Psicologia no conjunto das ações consideradas prioritárias para a política pública em questão, o que ocasiona uma ambiguidade.

Incorporar as questões sociais às intervenções em Psicologia não significa realizar o trabalho que o/a assistente social sabe fazer, e sim realizar o trabalho de intervir com o objetivo de minimizar o sofrimento psíquico, considerando que na construção desse sofrimento há um processo social, histórico e cultural que constitui a inequidade de gênero, mas o objetivo do trabalho não mudaria.

O discurso de que as psicólogas precisam assumir seu lugar nas questões dos direitos humanos e nos processos sociais, que constroem situações de adoecimento e sofrimento psíquico, parece que está sendo utilizado de forma a haver um afastamento da possibilidade de oferecer oportunidade de acolhimento do sofrimento e da dor psíquica, e de autoconhecimento. E o que se percebeu é que a intervenção que trabalhe a subjetividade é fundamental; e, junto com a emancipação material e financeira, a busca pelos direitos constitucionais, a compreensão histórica e cultural da submissão das mulheres aos homens, construiriam um processo de empoderamento mais amplo e consistente.

\section{Referências}

Arán, M. (2009). A psicanálise e o dispositivo diferença sexual. Revista EstudosFeministas,17(3), 653-673. Recuperado de <http://www.scielo.br/pdf/ref/v17n3/ v17n3a02>

Bardin, L. (2011). Análise de Conteúdo. Lisboa: Edições 70. Bastos, V. B., Gondim, S. M. G., \& Rodrigues, A. C. A. (2010). Uma categoria profissional em expansão: quantos somos e onde estamos? A.V. B.Bastos, \&S.M.G. Gondim(2010). (Eds), O trabalho do psicólogo no Brasil.(pp. 32-44). Porto Alegre: Artmed.

Bourdieu, P. (2005). A dominação masculina. Rio de Janeiro: Bertrand Brasil.

Brandão, E. R. (1998). Violência conjugal e o recurso feminino à polícia. In C. Bruschini., \& H. B. Hollanda (Orgs.). Horizontes plurais: novos estudos de gênero no Brasil. (pp. 51-84). São Paulo: Editora 34/Fundação Carlos Chagas.

Brasil. Presidência da República, Secretaria Especial de Políticas para as Mulheres.(2003). Programa de Prevenção, Assistência e Combate à Violência Contra a Mulher -
Plano Nacional: diálogos sobre violência doméstica e de gênero:construindo políticas públicas. Brasília: A Secretaria. Brasil. Presidência da República, Secretaria Especial de Políticas para as Mulheres. (2005a). Termo de Referência Casa-abrigo. Portaria $n^{\circ}$ 003, de 24 de março de 2005. Brasília: Autor.

Brasil. Presidência da República, Secretaria Especial de Políticas para as Mulheres. (2005b). Termo de Referência. Centro de referência e atendimento à mulher. Portaria $n^{\circ}$ 003, de 24 de março de 2005. Brasília: Autor.

Brasil. Presidência da República, Secretaria Especial de Políticas para as Mulheres. (2006a). Termo de Referência. De 11 de janeiro de 2006. Brasília: Autor.

Brasil. Presidência da República, Secretaria Especial de Políticas para as Mulheres. (2006b). Norma Técnica de Uniformização: Centros de Referência de Atendimento àMulher em Situação de Violência. Brasília: Autor.

Brasil, Secretaria de Políticas para as Mulheres. (2015). Balanço 2015 - $1^{\circ}$ Semestre - LIGUE 180. Brasília: Autor. Recuperado de <http://www.spm.gov.br/assuntos/ 
violencia/ligue-180-central-de-atendimento-a-mulher/ balanco1sem2015-versao-final.pdf>

Butler, J.(1990). Gender trouble. Feminism and the Subversion of Identity. NewYork: Routledge.

Butler, J. (1992). Problema de los géneros, teoría feminista y discurso psicoanalítico.In J. L. Nicholson (Ed.), Feminismo/posmodernismo. (pp. 75-95). Buenos Aires:Feminaria Editora.

CFP - Conselho Federal de Psicologia. (2012). Referências técnicas para atuação de psicólogas(os) em Programas de Atenção à Mulher em situação de Violência. Brasília: CFP.

De Lauretis, T. (1987). Technologies of gender, essays on theory, film and fiction. Bloomington, Indiana: University Press.

Dieese - Departamento Intersindical de Estatística e Estudos Socioeconômicos. (2011). Anuário das mulheres brasileiras. São Paulo; Dieese.

Diniz, G. (2011). Conjugalidade e violência: reflexões sob a ótica de gênero. In T. Ferés-Carneiro (Org.), Casal e família: conjugalidade, parentalidade e psicoterapia(pp. 11-26).São Paulo: Casado Psicólogo.

Garcia, M. V., Ribeiro, L. A., Jorge, M. T., Pereira, G. R., \& Resende,A. P. (2008). Caracterização dos casos de violência contra a mulher atendidos em três serviços nacidade de Uberlândia, Minas Gerais, Brasil. Cadernos de Saúde Pública, 24(11),2551-2563.

Hanada, H., D’Oliveira, A. F. P. L.,\&Schraiber, L. B. (2010). Os psicólogos na rede de assistência a mulheres em situação de violência. Revista de Estudos Feministas, 18(1),33-60.Recuperado de <http://www.scielo.br/pdf/ ref/v18n1/v18n1a03>

Hanada, H., D’Oliveira, A. F. P. L., \& Schraiber, L. B. (2008). Os psicólogos e a assistênciaa mulheres em situação de violência. Fazendo Gênero 8 - Corpo, Violência e Poder. Florianópolis, de 25 a 28 de agosto de 2008.
Machado, C. (2004). Intervenção psicológica com vítimas de crimes: dilemas teóricos,técnicos e emocionais. International Journal of Clinical and Health Psychology, 4(2),399-411. Recuperado de <http://www.redalyc.org/ html/337/33740211/>

Menezes, L. S.(2012). Desamparo. (Coleção Clínica Psicanalítica). São Paulo: Casa do Psicólogo.

Oliveira, D.C.,\& Souza, L. (2006). Gênero e violência conjugal: concepções depsicólogos.Estudos e Pesquisa em Psicologia, 6(2), 34-50.Recuperado de <http://www. redalyc.org/html/4518/451844612006/>

Porto, M., \&Bucher-Maluschke, J. S. N. F. (2012). Atendimento psicológico e a Secretaria de Políticas para as Mulheres. Psicologia \& Sociedade, 24(3), 567-576. Recuperado de <http://www.redalyc.org/ $\mathrm{html} / 3093 / 309326585009 />$

Porto, M., \& Bucher-Maluschke, J. S. N. F. (2014). A permanência de mulheres emsituações de violência: considerações de psicólogas. Psicologia: Teoria e Pesquisa, 30(3), 267-276. Recuperado de: <http://revistaptp.unb.br/index.php/ptp/article/ view/1885/704>

Rubin, G. (1993). Otráfico de mulheres: notas sobre a "economia política” do sexo.(C. R. Dabat, Trad.) Recife: SOS Corpo.

Swain, T. N. (2006). Entre a vida e a morte, o sexo. Revista Labrys Estudos Feministas, 10(s/v). Recuperado de <http://intervencoesfeministas.mpbnet.com.br/textos/ tania-entre_a_vida_ea_morte.pdf>

Zanello, V. (2016). Saúde mental, gênero e dispositivos. In: M. Dimenstein, J. Leite, J.P. Macedo,\& C. Dantas (Org,). Condições de vida e saúde mental em contextos rurais (pp. 223-246). São Paulo, Intermeios; Brasília, CNPq; Natal, UFRN; Terezina, UFPI; Fapepi. 